NOTES

\title{
Correlationship between Amorphous Supermolecular Structure and Dyeability of As-Spun and Heat-Treated Poly(ethylene terephthalate) Fibers Spun at High Wind-Up Speeds
}

\author{
Kenji Kamide, Tomio KurIKI, and Sei-ichi MANABE \\ Fundamental Research Laboratory of Fiber and Fiber-Forming Polymers, \\ Asahi Chemical Industry Co., Ltd., 11-7 Hacchonawate, \\ Takatsuki, Osaka 569, Japan \\ (Received July 5, 1985)

\begin{abstract}
KEY WORDS Amorphous Region/Supermolecular Structure/Poly(ethylene terephthalate) / Heat-Treatment / Dynamic Loss Tangent / Dyeability /
\end{abstract}

As is well-known, poly(ethylene terephthalate) (PET) fibers are dyeable with disperse dyes only above $120^{\circ} \mathrm{C}$ without the help of a carrier reagent. That is, PET fibers are usually difficult to be dyed in boiling water under atmospheric pressure.

The structural factors controlling the dyeability of PET fibers by the disperse dyes have not yet been systematically studied. Recently, the crystallinity ${ }^{1,2}$ and the optical birefringence $^{2}$ were chosen as parameters correlating with dyeability. However, note that these reflect strongly the crystalline supermolecular structure, in which dyestuff molecules are usually difficult to penetrate, rather than the amorphous supermolecular structure. Kitamura et al. $^{3}$ found that the penetration coefficient of a dye in heat-treated PET fibers increased with the intensity of the X-ray small angle scattering and the gauche content of the ethyleneglycol unit in the amorphous region. With an increase in the temperature or time of heat-treatment, the X-ray intensity increased and the gauche content decreased. Yonetake et al. $^{4}$ applied the mosaic-block model for the dyeability of heat-treated polypropylene films, and found that the crystallinity and the crystalline size especially in the direction of chain axis increase with heat- treatment as shown by the X-ray diffraction method, and then concluded that dye molecules were more absorbed in the amorphous side region located between cores parallel to the chain axis than in the amorphous end region between lamella surfaces. However, these studies lack in the direct evaluation of the fine structure of the amorphous region. Nakayama et $a .^{5}$ tried, in the case of poly(acrylonitrile) fibers, to correlate the amorphous molecular packing density distribution of the original samples with the dyeability by disperse dyes.

In this article, an attempt was made to establish more quantitative relations between the amorphous supermolecular structure and dyeability of PET fibers.

\section{EXPERIMENTAL}

\section{PET Fibers}

As-spun PET fibers were prepared at a spinning velocity $V_{\mathrm{s}}$ of $2-9 \mathrm{~km} \mathrm{~min}^{-1}$ and used without any further treatment. PET fibers spun at $V_{\mathrm{s}}=3.0,4.5,5.5$ and $8.0 \mathrm{~km} \mathrm{~min}^{-1}$ were annealed at a temperature $T_{\mathrm{a}}$ ranging $190-260^{\circ} \mathrm{C}$ for a time $t_{\mathrm{a}}$ less than $2 \mathrm{~s}$ at a constant length (i.e., under zero over feed).

PET fibers were stored over silica gel in a 
desiccator until just before the measurements of dye exhaustion and viscoelastic properties. Note that all PET samples were consisted of 36 filaments and each filament had same diameter (ca. $14.6 \mu \mathrm{m}$ ) as expressed by denier of $75 / 36$.

\section{Dye Exhaustion}

Two kinds of disperse dyes were used as received: Diacelliton Fast Orange GL manufactured by Mitsubishi Chemical Co. (CI Disperse Orange 3; 4-nitro-4'-aminoazobenzene, molecular weight: 246) (referred to as DFO) and Resolin Blue FBL manufactured by Bayer (CI Disperse Blue 56; 1,5-diamino-2-bromo-4,8-dihydroxyanthraquinone, molecular weight: 349) (referred to as FB). PET filaments were cut to give short fibers of $1 \mathrm{~cm}$ in length and $3 \mathrm{~g}$ of the fibers was used for further dyeing experiments as follows: dyeing temperature, $100^{\circ} \mathrm{C}$ : liquor ratio, $1: 50$; dye concentration, $0.6 \mathrm{gl}^{-1} ; \mathrm{pH}, 6$; dyeing time, $60 \mathrm{~min}$. After $60 \mathrm{~min}$-dyeing, a $0.5 \mathrm{ml}$ of the dyeing liquor was dissolved in $10 \mathrm{ml}$ of a water-acetone (volume ratio $1: 1$ at $20^{\circ} \mathrm{C}$ ) mixture. The absorbance at $450 \mathrm{~nm}$ (DFO) and $625 \mathrm{~nm}$ (FB) of the solution, $A_{60}$, was determined on a Shimadzu doublebeam spectrophotometer UV-360. The dye exhaustion was calculated by the formula,

Dye exhaustion $=\left[\left(A_{0}-A_{60}\right) / A_{0}\right] \times 100(\%)$ where $A_{0}$ is the absorbance of the starting dye solution.

The effects of $V_{\mathrm{s}}$ on the dye exhaustion for as-spun PET fibers are most remarkable at 60 min-dyeing (as shown in Figure 1), but the dye exhaustion for heat-treated PET fibers attains approximately an assymptotic value within $60 \mathrm{~min}$ of dyeing (Figure 2). Then, the dye exhaustion after $60 \mathrm{~min}$-dyeing for as-spun fibers may reflect the diffusion velocity of the dye molecules into the fiber solid and that for heat-treated fibers is closely associated with equilibrium dye uptake.

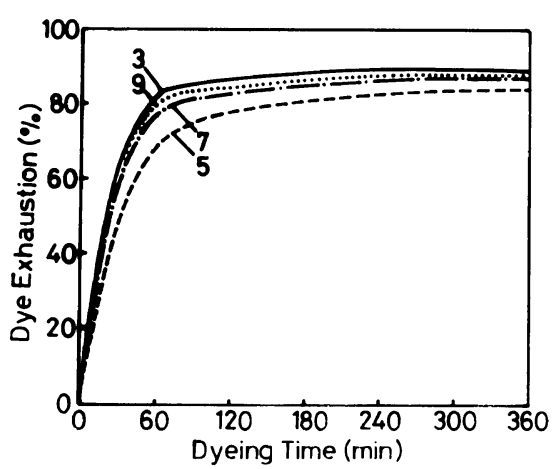

Figure 1. Rate of dye exhaustion for as-spun PET fibers spun at $V_{\mathrm{s}}$ of $3,5,7$, and $9 \mathrm{~km} \mathrm{~min}^{-1}$ by Resolin Blue FBL. Number denotes $V_{s}$.

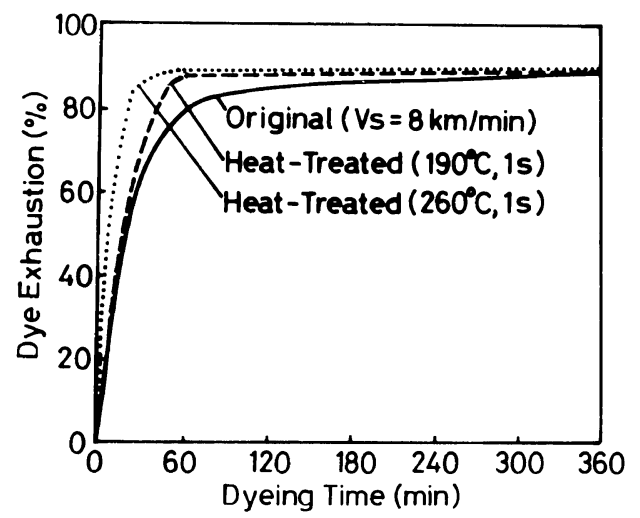

Figure 2. Rate of dye exhaustion for as-spun and heattreated fibers spun at $V_{\mathrm{s}}$ of $8 \mathrm{~km} \mathrm{~min}^{-1}$ by Resolin Blue FBL.

\section{Viscoelastic Property}

Dynamic mechanical loss tangent $\tan \delta$ at $110 \mathrm{~Hz}$ of the PET fibers measured by a ToyoBaldwin Rheovibron DDV-IIc at a heating rate of $10 \mathrm{~K} \mathrm{~min}^{-1}$.

\section{RESULTS AND DISCUSSION}

Figure 3 shows the spinning velocity dependence of dye exhaustion of as-spun fibers. In the figure, the filled mark indicates FB and the unfilled mark, DFO. The dyeability of PET fibers changes remarkably depending on $V_{\mathrm{s}}$ and becomes minimum at $V_{\mathrm{s}}=5 \mathrm{~km} \mathrm{~min}^{-1}$. In the range of $V_{\mathrm{s}}<5 \mathrm{~km} \mathrm{~min}^{-1}$, with an increase 


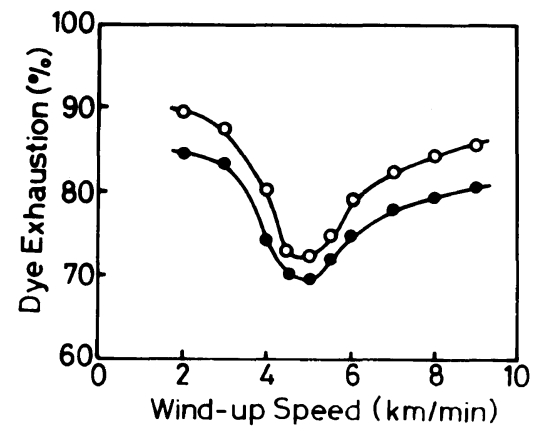

Figure 3. Plot of the dye exhaustion of as-spun PET fibers by Diacelliton Fast Orange GL and Resolin Blue FBL as a function of the spinning velocity $V_{s}$ : unfilled mark, Diacelliton Fast Orange GL; filled mark, Resolin Blue FBL; dyeing temperature, $100^{\circ} \mathrm{C}$; dyeing time, $60 \mathrm{~min}$.

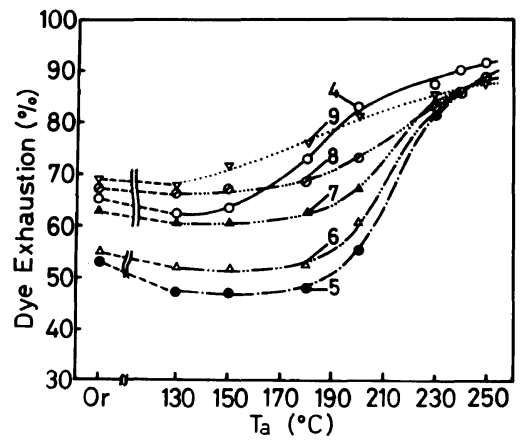

Figure 4. Change in the dye exhaustion of PET fibers spun at $V_{\mathrm{s}}=4-9 \mathrm{~km} \mathrm{~min}^{-1}$ and treated at the annealing temperature $T_{\mathrm{a}}$ for $1 \mathrm{~s}$; Or indicates unannealed as-spun fibers; dye, Resolin Blue FBL.

in $V_{\mathrm{s}}$ the amorphous region begins to crystallize during the melt-spinning process concurrently, and thus the remaining amorphous region becomes more closely packed. In addition, as-spun PET fibers change significantly in their structure during the dyeing process $\left(100^{\circ} \mathrm{C} \times 60 \mathrm{~min}\right.$ in water $)$. In the range $V_{\mathrm{s}}>5 \mathrm{~km} \mathrm{~min}^{-1}$, the above-mentioned change in supermolecular structure can almost be ignored.

Similar relations between dye exhaustion and $V_{\mathrm{s}}$ were found for other dyes. The dye exhaustion is larger for DFO than for FB; the smaller dyestuff molecule yields larger dye-

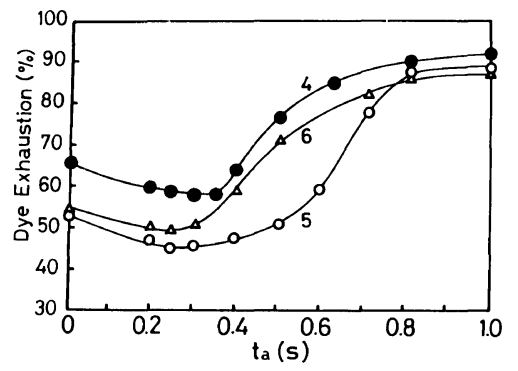

Figure 5. Effects of annealing time $t_{\mathrm{a}}$ on the dye exhaustion of PET fibers spun at $V_{\mathrm{s}}=4,5$, and $6 \mathrm{~km}$ $\min ^{-1}$ and annealed at $T_{\mathrm{a}}=250^{\circ} \mathrm{C}$ : Number denotes $V_{\mathrm{s}}$; dye, Resolin Blue FBL; dyeing temperature, $100^{\circ} \mathrm{C}$; dyeing time, $60 \mathrm{~min}$.

ability if the other physical properties are not so different.

Figure 4 shows the effects of annealing temperature $T_{\mathrm{a}}$ on the dye exhaustion of PET fibers spun at $V_{\mathrm{s}}=4-9 \mathrm{~km} \mathrm{~min}^{-1}$ and annealed for $1 \mathrm{~s}$ at $T_{\mathrm{a}}$. The dye exhaustion of PET fibers reveals minimum at $T_{\mathrm{a}}=130$ $180^{\circ} \mathrm{C}$. Almost the same curves were obtained for PET fibers spun at different $V_{\mathrm{s}}$ and subsequently annealed. Note that $130-180^{\circ} \mathrm{C}$ coincides roughly with $T_{\mathrm{a}}$ at which $T_{\max }$, the peak temperature of $\tan \delta$, of annealed PET fibers becomes maximum.

Figure 5 shows the relation between the dye exhaustion and $t_{\mathrm{a}}$ for PET fibers spun at $V_{\mathrm{s}}=4,5$ and $6 \mathrm{~km} \mathrm{~min}^{-1}$ and annealed at $T_{\mathrm{a}}=250^{\circ} \mathrm{C}$ for different $t_{\mathrm{a}}$. With an increase in $t_{\mathrm{a}}$, the dye exhaustion decreases first and then increases after passing a minimum. Large $V_{\mathrm{s}}$ gives smaller $t_{\mathrm{a}}$, corresponding to minimum exhaustion $\left(t_{\mathrm{a}, \mathrm{m}}\right)$.

In the range $t_{\mathrm{a}}<t_{\mathrm{a}, \mathrm{m}}$, the recrystallization due to the heat-treatment occurs and in the range $t_{\mathrm{a}}>t_{\mathrm{a}, \mathrm{m}}$, the packing density of the amorphous region becomes lower. Figure 3 indicates that during the heat-treatment, recrystallization occurs first and then loosening of amorphous region begins. The $t_{\mathrm{a}, \mathrm{m}}$ is in good agreement with $t_{\mathrm{a}}$ which gives maximum of $T_{\max }$ for annealed fibers.

Figure 6 shows the relation among the peak 


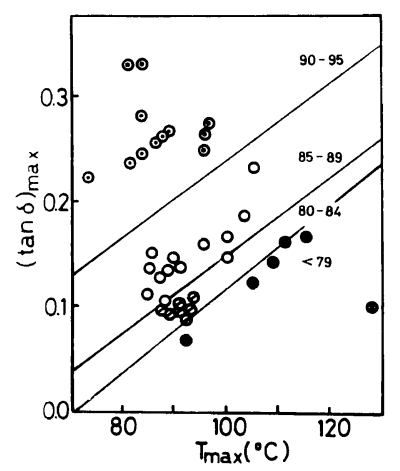

Figure 6. Correlation among $(\tan \delta)_{\max }, T_{\max }$ and dye exhaustion for as-spun PET fibers annealed under various conditions: $\odot$, dye exhaustion $=90-95 \%$; $\bigcirc$, dye exhaustion $=85-89 \%$; $\oslash$, dye exhaustion $=80-84 \%$; $\bigcirc$, dye exhaustion $\leqq 80 ; \otimes$, conventional drawn PET fiber $\left(V_{\mathrm{s}}=1.5 \mathrm{~km} \mathrm{~min}^{-1}\right.$, draw ratio=3.9), dye exhaustion $=26 \%$. Number means dye exhaustion $(\%)$.

values of $\tan \delta\left[(\tan \delta)_{\max }\right], T_{\max }$ and the dye exhaustion for PET fibers. In the figure, the number indicates the dye exhaustion. Here, all the samples were confirmed not to change their supermolecular structure in the amorphous region during the dyeing $\left(100^{\circ} \mathrm{C}, 60 \mathrm{~min}\right.$ in water) process by measurement of their $\tan \delta$ temperature curves before and after dyeing. Each value of dye exhaustion except that of the conventional drawn fiber corresponds to the equilibrium dye uptake.

Provided that other structural factors than $(\tan \delta)_{\max }$ and $T_{\max }$ are the same, the dyeable part of the fibers is expected to be determined by $F^{\prime}(n)^{6-10}$, which is a function of $(\tan \delta)_{\max }$ and $T_{\max }$. Then, $(\tan \delta)_{\max }$ and $T_{\max }$ should be useful as parameters representing the dyeability. In particular, $(\tan \delta)_{\max }$ and $T_{\max }$ represent the amount and molecular packing density of the amorphous region, respectively.

PET fibers with larger $(\tan \delta)_{\max }$ and lower $T_{\max }$ are more easily dyeable and have higher equilibrium dye uptake, and the reverse is true. Figure 6 indicates that the dyeability is almost unanimously determined by $(\tan \delta)_{\max }$ and $T_{\max }$, irrespective of the preparative con-

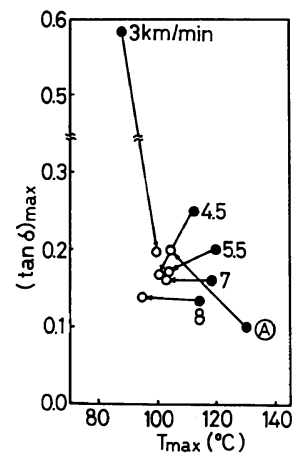

Figure 7. Change in $(\tan \delta)_{\max }$ and $T_{\max }$ of as-spun PET fibers by heat-treatment: Number is $V_{\mathrm{s}}$ in $\mathrm{km} \mathrm{min}{ }^{-1} ; A$ is conventional drawn PET fibers.

ditions. There is no significant correlation between the dye exhaustion and the crystallinity of the fibers.

Figure 7 shows the change in $(\tan \delta)_{\max }$ and $T_{\max }$ for PET fibers by the adequate heattreatment. The number on curve means $V_{\mathrm{s}}$. We can control the amorphous supermolecular structure of as-spun fibers having largely scattered $(\tan \delta)_{\max }$ and $T_{\max }$ by applying adequate heat-treatment.

According to the results of Figures 6 and 7, the dyeability of PET fiber is also controllable by selecting heat-treatment conditions. Consequently, it is possible to make PET fibers dyeable under atmospheric pressure.

\section{REFERENCES}

1. R. H. Peters, Colour Age, November, 4, 3 (1982).

2. R. A. F. Moore and H. D. Waigmann, Text. Chem. Colour., 15, 197 (1983).

3. K. Kitamura, F. Shibata, and Z. Yoshida, Sen- $i$ Gakkaishi, 8, 359 (1971).

4. K. Yonetake, T. Masuko, T. Shimanuki, and M. Karasawa, J. Appl. Polym. Sci., 28, 3049 (1983).

5. C. Nakayama, K. Kamide, and S. Manabe, Sen- $i$ Gakkaishi, 33, T192 (1977).

6. S. Manabe, K. Kamide, and C. Nakayama, J. Text. Mach. Soc. Jpn., 30, T45 (1977); and also J. Text. Mach. Soc. Jpn., English Edition, 26, 1 (1980).

7. S. Manabe, K. Kamide, and C. Nakayama, J. Text. Mach. Soc. Jpn., 30, T55 (1977); and also J. Text. Mach. Soc. Jpn., English Edition, 26, 42 (1980).

8. S. Manabe, K. Kamide, and C. Nakayama, J. Text. 


\section{Amorphous Structure and Dyeability of PET fibers}

Mach. Soc. Jpn., 30, T66 (1977); and also J. Text. Mach. Soc. Jpn., English Edition, 26, 65 (1980).

9. S. Manabe, K. Kamide, C. Nakayama, and S. Kobayashi, J. Text. Mach. Soc. Jpn., 30, T85 (1977); and also J. Text. Mach. Soc. Jpn., English Edition, 27, 10 (1981).

10. S. Manabe and K. Kamide, Polym. J., 16, 375 (1981). 